\title{
Facilitating cross-border rural micro-firm knowledge exchange
}

\section{A community of practice perspective}

\author{
Leana Reinl, Eleanor Owens, Felicity Kelliher and \\ Denis Harrington
}

\begin{abstract}
Knowledge sharing enhances the capability of rural microfirms to facilitate economic growth, competitiveness and employment. Knowledge exchange research predominantly focuses on larger firms in the same or related industries, and is of limited relevance in a rural micro-firm context, owing to significant differences in resource availability which can result in strategic knowledge constraints and the meagre development of micro-firms and the regions in which they resideloperate. The aim of this research is to explore the knowledge exchange criteria of rural micro-firms in a cross-border facilitated learning network (FLN). Drawing on the 'community of practice' perspective and the closely connected learning network literature, the authors observe and map FLN knowledge exchange activities over a three-year period. The resultant rural FLN knowledge exchange framework demonstrates that discipline and sector-specific barriers can be overcome through cyclical FLN interventions sensitive to the social proximity requirements necessary for effective cross-border knowledge exchange.
\end{abstract}

Keywords: knowledge exchange; rural micro-firms; cross-border; facilitated learning network; community of practice

Leana Reinl (corresponding author) is an Irish Research Council Postdoctoral Fellow in the School of Business at Waterford Institute of Technology, Applied Technology Building, Cork Road, Waterford, Ireland. E-mail: lreinl@wit.ie. Eleanor Owens is the MSc in Science Education Programme Director, Felicity Kelliher is Senior Lecturer in Management Studies and Co-Chair of the Rikon Research Group, and Denis Harrington is Head of Graduate Business, all at the Waterford Institute of Technology.

This paper explores the knowledge exchange criteria of rural micro-firms in a cross-border facilitated learning network (FLN), seeking to promote stakeholder engagement with the green economy in Ireland and Wales, and proposes a framework of FLN knowledge exchange based on the findings. Rural business communities are defined by their small-scale, peripheral nature and the specialization of their economic/industry base (Deavers, 1992). These rural business communities are dominated by micro-firms and rely on them to facilitate economic growth, competitiveness and employment (Murdoch, 2000; Phillipson et al, 2004; Reinl and Kelliher, 2014). Micro-firms are demarcated as commercial entities employing 10 people or fewer (European Commission, 2011) and are the target rural group relating to this study.

The constrained resource realities of micro-firms (Devins et al, 2005; Kelliher and Reinl, 2009) result in 
knowledge demands which centre on the acquisition of immediately applicable solutions to urgent operational needs of the business (Noel and Latham, 2006). Limited engagement in knowledge exchange activities inhibits micro-firm development (Kelliher et al, 2014; Phillipson et al, 2004) and may eventually contribute to business failure (Comhar Sustainable Development Council, 2009). As a result, these firms are encouraged to develop knowledge exchange relationships which have the potential to enhance their business capabilities, open resource channels and/or improve their competitive position (Kearney et al, 2014). Integrated stakeholder engagement between government agencies, higher education institutes, indigenous businesses, economic support groups and rural development groups (Döring and Schnellenbach, 2006; Drda-Kühn and Wiegand, 2010; Kelliher et al, 2014) are of value in this regard. However, such knowledge relationships are reliant on exchange behaviours to develop (Mäkinen, 2002; Reinl and Kelliher, 2010; Tell, 2000) and to sustain value over time (Reinl and Kelliher, 2014).

One such means is through a facilitated learning network (FLN): 'a network formally set up for the primary purpose of increasing knowledge' (Bessant and Tsekouras, 2001, p 88), in which stakeholder knowledge is leveraged through facilitated learning processes and relationships. Here, members can seek solutions to specific knowledge requirements in the network, which can act as a vehicle for sustained knowledge exchange. Ideally, this exchange activity should lead to a 'community of practice' (CoP) ethos (Lave and Wenger, 1991; Morrison et al, 2004) over time, in which members share a concern or a passion for something they do and learn how to do it better as they interact regularly (Wenger et al, 2008). Drawing from this CoP perspective (Lave and Wenger, 1991; Wenger et al, 2008), the literature review considers the nature of knowledge exchange in a rural micro-firm FLN context before contemplating the expansion of knowledge exchange boundaries across disciplines and across local, regional and national borders. The ultimate objective of an FLN of this nature is sustainable knowledge exchange relations, and the underlying goal is to discover, understand and perhaps improve on existing patterns and order (Ghaye and Lillyman, 1997) in order to 'do it better' (Wenger et al, 2008).

The emergent literary criteria guided the action research approach adopted. Over a three-year period, these knowledge criteria were observed and catalogued on a cross-border inter-regional (INTERREG) FLN.

INTERREG is an EU community programme that aims to strengthen economic and social cohesion by promoting international and cross-border cooperation between regions in the EU; this research specifically focuses on the Irish and Welsh cross-border INTERREG regions (see Figure 1).

Considering the value that FLN engagement offers to individual micro-firms and the rural locales in which they reside/operate, there is merit in pursuing a framework to support knowledge activity among this cohort. Therefore, the findings inform the proposed framework of rural FLN knowledge exchange (Figure 2). The research is of interest to rural development policy makers and government agencies seeking to support the development of rural business communities. The findings also offer guidance to rural micro-firm practitioners seeking to develop effective knowledge exchange connections within and beyond their traditional business community boundaries.

\section{Rural micro-firm cross-border knowledge exchange}

Being embedded in their local communities (Freel, 1999), rural micro-firms exchange knowledge in situ within a set of localized interactive relationships (Aylward, 2012; Reinl and Kelliher, 2010). Sharing a concern for the pursuit of knowledge or activity of some kind, stakeholders interpret meaning as they interact with one another during the course of their everyday work practices and routines (Lave and Wenger, 1991). Despite this proximity, stakeholder ties to family (Wheelock and Baines, 1998) and the local and wider business community (Devins et al, 2005; Phillipson et al, 2006), including business advisers, can remain inert unless unlocked by owner/manager capability (Kearney et al, 2014). Lacking the expertise to identify knowledge gaps or the behavioural changes associated with meeting them (Freel, 1999; Garavan et al, 2004), micro-firm owner-managers tend not to reach too far beyond the immediate boundaries of their local business environs in order to connect with providers of specialist knowledge. As such, barriers to innovation are deeply embedded at owner-manager level in these firms (Kearney et al, 2014); however, these barriers may be alleviated using cross-border FLNs.

Action-focused short-term knowledge goals dominate more strategic goals in a micro-firm environment (Noel and Latham, 2006; Reinl and Kelliher, 2010) and limit their ability to engage in and benefit from broader strategic knowledge exchange processes. As a result, knowledge exchanges tend to be a reactive by-product of a business process rather than a process in itself (Devins et al, 2005). Hence external catalysts are often required to trigger micro-firm knowledge exchange (Kelliher and Reinl, 2009), and FLNs are endorsed to support such exchanges (Mäkinen, 2002; Reinl and Kelliher, 2010; Tell, 2000). An FLN is 'a network 
formally set up for the primary purpose of increasing knowledge' (Bessant and Tsekouras, 2001, p 88), while a multidisciplinary, cross-border FLN has the primary purpose of expanding knowledge exchange beyond the boundaries of a single rural business community. Here, knowledge is leveraged through facilitated learning processes and relationships, embedding an emergent international community of practice wherein members can seek solutions to specific knowledge requirements (Lave and Wenger, 1991; Morrison et al, 2004; Wenger et al, 2008).

Academics from a variety of disciplines and/or local, regional, national and international authority actors (Haugen Guasdal, 2008) assume the role of 'knowledge brokers' supporting cross-border knowledge exchange on a continuous and interim basis as appropriate (Jack et al, 2004; Reinl and Kelliher, 2014). They provide connections between smaller firms and relevant experts (von Malmborg, 2007), regardless of location, and facilitate access to otherwise unavailable knowledge and resources (Chell and Baines, 2000; Kelliher et al, 2014). These brokers utilize narrative knowledge exchange frameworks (Reinl and Kelliher, 2010; Tell, 2000) to prompt experience sharing (Mäkinen, 2002) and encourage questioning among network members. In doing so, FLN knowledge brokers hone the evaluation skills of micro-firm owners/managers and enable them to gauge the quality of knowledge exchanges for themselves (Reinl and Kelliher, 2010) beyond the boundaries of their local rural community. As knowledge encompasses the beliefs and judgments arising from information analysis, the divergent motivations and knowledge bases of multi-level public and private FLN members offer knowledge exchange value. Furthermore, engagement beyond the borders of a single rural community provides a basis for both knowledge transfer and learning across network boundaries (Kelliher et al, 2014; Uzzi, 1997); thus learning sets have access to multidisciplinary expertise based in various locations within the INTERREG community.

FLN members are assigned to learning sets and are guided by experienced facilitators who encourage active participation and experience sharing (Devins et al, 2005; Kelliher et al, 2009). Previous research suggests that these sets should be as 'diverse as necessary and as similar as possible' (Halme, 2001, p 112) in order to challenge existing frames of reference and assist network members to develop an appreciation of the interdependencies of rural development and to negotiate sustainability issues (Halme, 2001; Lee et al, 2005). The set can then hone the 'requirements for collective action in their resolution' (Graci, 2013, p 36) using platforms which support dialogue and negotiation and permit network members to reach a level of shared meaning, which can in turn underpin longer-term knowledge exchange (Lave and Wenger, 1991; Reinl and Kelliher, 2014). Despite the value of difference noted above, a 'common language' approach is of particular importance in a cross-disciplinary network context (Swan et al, 2002) as discipline-specific knowledge may be so embedded within practice that exchanges may fail, even at a local level. Over time, cyclical FLN engagement should facilitate the emergence of a shared repertoire of stories, rules and routines, which permit community members to engage with one another effectively (Lave and Wenger, 1991; Wenger et al, 2008). In turn, a 'learning curriculum' should emerge through situated opportunities for the improvisational development of 'new practice' (Reinl and Kelliher, 2014; Wenger, 1998). This new practice should be evident in the field of resources and capabilities which network members create and leverage (Lave and Wenger, 1991) as a community of practice emerges.

Given the above discussion, it is evident that flows of knowledge are 'inextricably linked to the social relations which develop through shared practice' (Swan et al, 2002, p 479). However, it is also clear that the pursuit of effective rural micro-firm knowledge exchange may be challenging, particularly when engagement is beyond their discipline, their traditional business community and/or their knowledge exchange boundaries.

\section{Expanding knowledge exchange boundaries across disciplines and across borders}

Notwithstanding the fact that place-specific knowledge is crucial to micro-firm development (Brouder and Eriksson, 2013) and more broadly to sustainable rural development (Döring and Schnellenbach, 2006), microfirms have a tendency to overvalue local knowledge while overlooking other important market trends (Saxena and Ilbery, 2008) and information sources. In addition, the protectionism of regional and national boundaries can further hamper optimum knowledge flows (Kelliher et al, 2014). The resource constraints faced by many rural communities (in particular microfirm residents), coupled with a lack of sufficient convergence, can render network exchanges inefficient (Schaper, 2010). It follows that achieving the levels of social interaction required to fortify longer-term knowledge exchange (Haugen Gausdal, 2008; Lave and Wenger, 1991) is likely to be challenging in a rural setting.

While leveraging existing social structures that underpin collaboration and knowledge exchange within rural communities is advised (Phillipson et al, 2006; Reinl and Kelliher, 2014), knowledge brokers should 
also seek to expand the networks' boundary to include international actors (Erkuş-Öztürk, 2009). Opening restrictive knowledge flows in this way should help to alleviate 'spatial blindness' (Brouder and Eriksson, 2013). Virtual and physical forums offer 'collaborative space' where geographically distant members, sharing domain-/discipline-specific experience and knowledge requirements can meet and participate in broader knowledge exchange pools. Network 'champions', as in situ knowledge brokers (Phillipson et al, 2006; Reinl and Kelliher, 2014), can readily translate local knowledge (Breschi and Lissoni, 2003) across geographical borders, while FLN brokers connect local network members with providers of specialist knowledge facilitating multi-level knowledge exchange in an international context (Halme, 2001).

Given that network members decide what competence is, attention must be paid to legitimizing 'expert identities' across the wider community (Wenger, 1998); this is particularly important where network members are geographically distant from each other (Parry, 2012). Considering micro-firms' preference to learn from experience and from one another and acknowledging their propensity for immediately applicable information, 'real world' case examples and study tours offer knowledge exchange value. By highlighting working ideas, they permit dialogue and reflection on live business development projects and processes (Fiol and Lyles, 1985; Halme, 2001), potentially transforming perspectives and unveiling new strategic development paths (Reinl and Kelliher, 2014). The knowledge exchange criteria outlined above are catalogued in Table 1.

\section{A cross-border FLN to promote knowledge exchange}

\section{Background to the cross-border FLN}

In 2011, an interdisciplinary team of academics and project specialists in Ireland and Wales collaborated on a cross-border INTERREG-funded initiative entitled the Green Innovation and Future Technologies (GIFT) project, a capstone of which was the establishment and development of an FLN comprising local, national and international stakeholders within the Welsh and Irish INTERREG regions (Figure 1).

Although the Irish and Welsh regions differ to some degree in terms of their proximity to other rural businesses, to knowledge exchange stakeholders and to urban centres, the micro-firm FLN participants share an interest in green business development and also suffer impeded connections to broader strategic knowledge pools due to their rural location. Rural areas differ greatly within the EU, and definitions from the Organisation for Economic Cooperation and Development (OECD), European Council and European Commission vary, taking into account several criteria including population, proximity to urban centres, occupation of space, employment and use of land. No longer viewed from a dominant agricultural perspective, rural business occupies various sectors and encompasses a wide range of practices and activities which are spatially bounded (Deavers, 1992; Marsden et al, 1990).

A core aim of the three-year GIFT project is to engage rural micro-firms and stakeholders representing local and national authorities, business support bodies and government policy actors in the green economy and stimulate knowledge exchange activities among them.

Table 1. Rural micro-firm knowledge exchange criteria.

\begin{tabular}{|c|c|c|c|}
\hline Knowledge exchange (KE) & Micro-firm & Cross-border FLN & Barrier release \\
\hline Initiating knowledge exchange & $\begin{array}{l}\text { Un-learning: reactive } \\
\text { action emphasis. } \\
\text { Preference to learn from } \\
\text { one another and from } \\
\text { experience. }\end{array}$ & $\begin{array}{l}\text { Narrative KE frameworks. } \\
\text { Collegial learning spaces. } \\
\text { FLN resources (stories, } \\
\text { case studies and routines) } \\
\text { support KE. }\end{array}$ & $\begin{array}{l}\text { Reflection embedded in 'real } \\
\text { world' examples of best practice } \\
\text { and failure. Idea generation basec } \\
\text { on previous experience coupled } \\
\text { with strategic guidance. Tacit loca } \\
\text { and discipline-specific knowledge } \\
\text { codified. }\end{array}$ \\
\hline Knowledge transfer and integration & $\begin{array}{l}\text { Knowledge is locally } \\
\text { constrained and } \\
\text { discipline-specific. }\end{array}$ & $\begin{array}{l}\text { Common language } \\
\text { approach. Multi-level/multi- } \\
\text { disciplinary negotiation } \\
\text { domains. Virtual learning } \\
\text { environment offers social } \\
\text { proximity. }\end{array}$ & $\begin{array}{l}\text { Diverse learning sets challenge } \\
\text { 'ways of doing'. Appreciation of } \\
\text { interdependence established. } \\
\text { Cross-border KE channels } \\
\text { established. }\end{array}$ \\
\hline Knowledge exploitation and leveraging & $\begin{array}{l}\text { Limited ability } \\
\text { (resources, skills and } \\
\text { behaviours) to engage } \\
\text { in broader knowledge } \\
\text { exchange relationships. }\end{array}$ & $\begin{array}{l}\text { Continued cyclical engage- } \\
\text { ment. Knowledge identities } \\
\text { legitimized. A shared } \\
\text { repertoire develops. }\end{array}$ & $\begin{array}{l}\text { Strategic KE behaviours develop. } \\
\text { Cooperative norms embedded in } \\
\text { individual and collective routines } \\
\text { and strategies. }\end{array}$ \\
\hline
\end{tabular}



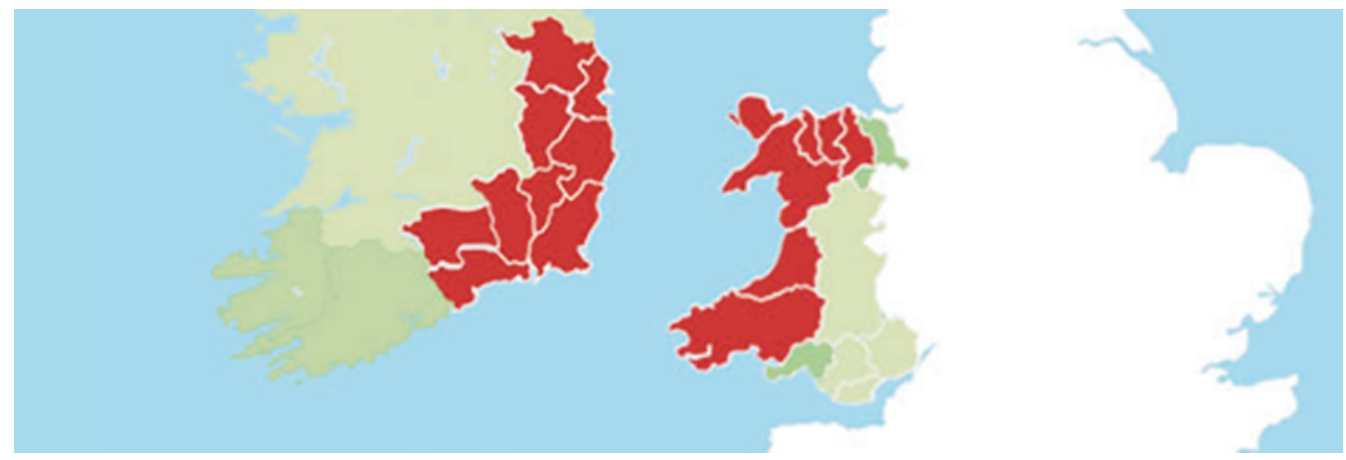

Figure 1. INTERREG regions of Ireland and Wales. Source: Southern and Eastern Regional Assembly, Ireland.

The green economy is 'a system of economic activities related to the production, distribution and consumption of goods and services which will result in improved human well-being over the long term, while not exposing future generations to significant environmental risks or ecological scarcities' (UNEP, 2011, p 16). The observed FLN comprises over 300 small and mediumsized enterprises (SMEs) based in Ireland and Wales; these are predominantly rural micro-firms operating businesses in energy, waste management, tourism, environmental consultancy, farming, forestry and manufacturing. The sector mix reflects the diversity and fragmentation that exist within the green SME sector in both jurisdictions (Government of Ireland, 2013; Welsh Government, 2009), and acknowledges the interdependencies of the green economy and rural/ sustainable development.

The FLN pursued solutions to development issues specific to the green economy, to the rural business owners and to their locales. Structured social learning processes sought to leverage multi-level stakeholder knowledge that was beyond the usual range of rural micro-firm knowledge exchange. As such, knowledge, perspectives and experiences are shared with Irish and Welsh partner institutions, agencies and companies to help establish innovative solutions in an effort to promote the green economy. FLN 'support hubs' comprise multidisciplinary senior academic advisers, a project manager, project coordinator and business development and theme officers across three higher educational institutes in Ireland and Wales. A series of thematic and specialized workshops, online discussions (via a virtual learning environment), international expert engagement and exhibited best practice case studies were offered to participants over the three-year project. In addition, a learning showcase and study tour were held in rotation each year in Ireland and Wales.

\section{Methodology}

As the aim of this research is to explore the knowledge exchange criteria of micro-firms within a cross-border FLN, and considering the depth of the authors' involvement in the FLN studied, an action research (AR) methodological approach is deemed optimal. This approach is endorsed in a micro-firm FLN context (Florén and Tell, 2004; Kelliher et al, 2009). Although this research study considers knowledge interactions between a community of rural micro-firms and other FLN stakeholders within and outside their regional borders, the unit of analysis is the individual rural micro-firm owner-manager. Given the cross-disciplinary, cross-border composition of the FLN, and acknowledging the interdependencies of sustainability issues and 'requirements for collective action in their resolution' (Graci, 2013, p 36), the AR team is also represented by a diverse international team of academics who assumed active roles on the FLN, including that of project coordinator, business development officer and senior academic liaison officers with specialisms in natural and traditional sciences, green technology, lifelong learning and rural and micro-firm learning networks. A data collection protocol developed from the theoretical themes identified in the literature (Table 1) guided the data collection and analysis (Eisenhardt, 1989) of the observed FLN over the duration of the programme.

As a methodology, AR involves the active intervention of researchers to reflect on practice and take action to improve that practice (Revans, 1998; Trehan and Pedler, 2011). In this study, the process outlined in Table 2 followed a sequence of stages that permitted problem diagnosis, planned action and reflection and led to an evaluation of the knowledge exchange value (Susman and Evered, 1978). Taking into account that knowledge lives in the very communities where it is co-created 
(Wenger, 1998), data collection techniques included the observation of over 30 physical and virtual FLN interventions carried out in Ireland and Wales, as these events encompass the process of knowledge exchange (Lave and Wenger, 1991; Toiviainen, 2007). In tandem, evaluations of each FLN intervention provided additional participant/stakeholder insights into knowledge exchange criteria. As the AR process evolved, planned focus group discussions captured the perspectives of local network champions and industry experts with regard to directing and improving future knowledge exchange interventions. Refinement followed a series of steps (Susman and Evered, 1978). Quarterly advisory board meetings and monthly GIFT team meetings comprised a debriefing (as utilized in Florén and Tell, 2004, for example) and 360-degree participant feedback. These meetings permitted the authors to 'step back' from the FLN and engage in reflexive questioning with strategic advisers to assess possibilities for change (Cunliffe, 2004) and support the collective amendment of FLN interventions.

Ultimately, the goal of the FLN is to embed a community of practice in which shared meaning is established and members can create, leverage and sustain their own learning curriculum and resources, thereby encouraging micro-firm autonomy over the knowledge exchange process (Reinl and Kelliher, 2014). The iterative multilevel approach described above is paramount in co-creating knowledge (Rigg, 2008) informed through cycles of reflection, change and action (Florén, 2003). This approach also facilitated the development of theory through action, guided by theory and supported and revised through evaluation (Susman and Evered, 1978). This approach is not without limitations. As the FLN had a defined lifespan of three years, the concern remains that in the absence of a facilitated learning environment, the gains made relating to micro-firm autonomy may be temporary and the CoP ethos will not remain embedded in the community. Furthermore, as the data to inform FLN amendment were collected 'in action' (Rigg, 2008) by the authors, the challenge of researcher bias is countered by the maintenance of researcher reflexive diaries (Herr and Anderson, 2005; Reason and Bradbury, 2006).

\section{Findings}

\section{Initiating knowledge exchange relationships}

Acknowledging that the establishment of a cross-border community of practice (Wenger, 1998) is reliant on the active participation of local, national and international actors operating in diverse disciplinary fields within the green economy, initial GIFT interventions sought to identify and engage key stakeholders to explore and understand the knowledge gaps and issues micro-firms face when trying to develop their respective businesses in the green economy. Marked differences in stakeholder objectives were noted at this initial stage: while agencies were preoccupied with achieving policy requirements, micro-firms were requesting basic green/ business skills interventions. Those engaged appreciated that,

'Yes there is a challenge here, a challenge to make it real for their day to day business. We can talk about national and EU policy ... but [the FLN is] ... stripping away all that and on a business to business level to get them chatting with each other.'

Micro-firm owners/managers reminded government and higher education institute representatives of their resource reality (Devins et al, 2005; Kelliher and Reinl, 2009) and business development isolation:

'We micro-businesses are hardly noticeable, but we are here and we need help to develop our businesses and keep them going.' (Micro-firm: green tourism education provider)

Stakeholders agreed that: 'micro enterprises are often left aside; maybe [the FLN] could help here' (stakeholder: Managing Director, National Green Business Accreditation Programme). Following these early insights, a virtual learning engagement protocol was developed to facilitate continued cross-border stakeholder engagement, to encourage dialogue between Welsh and Irish network members and, ultimately, to promote a sense of community (Lave and Wenger, 1991; Morrison et al, 2004). Throughout the three-year programme (2011-14), the FLN hub considered crossborder and cross-sector knowledge requirements in interaction with stakeholders at physical and virtual learning events. In turn, these informed the development of future FLN interventions.

Reflecting on GIFT's inaugural event held in Wales, the Director of the Environmental Protection Agency provided the Irish green economy viewpoint:

'It was the early stages, [the FLN team] weren't quite sure how to pitch it ... it was more about sustainable ideas in Wales ... a good selection of presentations and speakers ... a good mix.'

A subsequent Irish launch engaged over 100 stakeholders, predominantly micro-firms, and reinforced the appetite for green economy knowledge exchange and the cross-border ethos of GIFT. Brokers (FLN brokers and local theme champions) facilitated pre- 
Cross-border rural micro-firm knowledge exchange

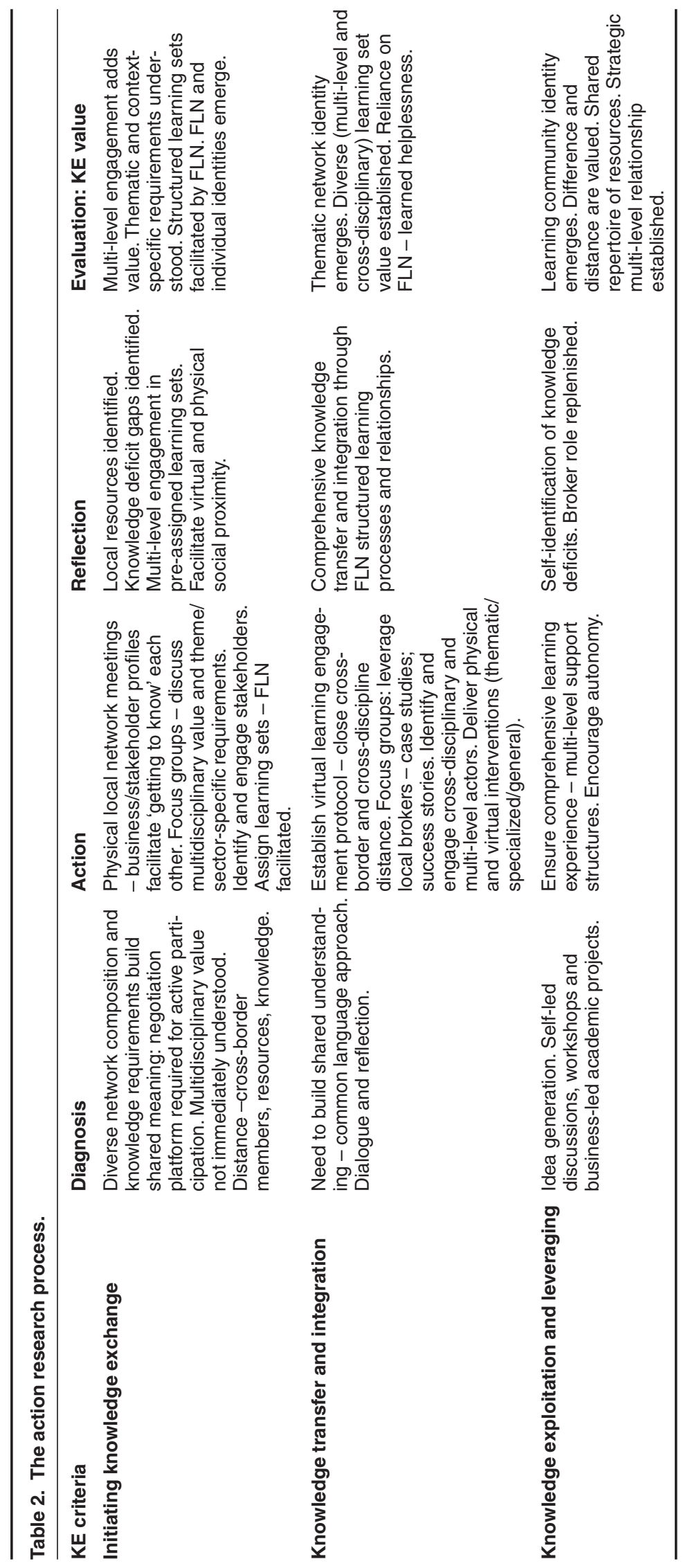


assigned discussion groups, seeking to tease out member knowledge requirements from the start (as recommended by Kelliher et al, 2009). Scribed focus group outcomes, academic liaison reports and FLN event evaluations revealed a diverse spectrum of needs and experience among those present and a desire from most for the FLN support hub to 'communicate environmentally-friendly operational practices' and leverage cross-border knowledge in context: 'Can we learn from ... Wales about engaging local communities in green initiatives?'; 'How do we include partners in Wales in terms of sharing of resources and academic expertise?'

Following the inaugural events in each location, case studies and business profiles were featured fortnightly on the FLN website and, in addition to the knowledge exchange benefits these provided, the profiles enabled geographically distant members to 'get to know one another'. Initial face-to-face and virtual debates centred on divergent objectives and business development approaches, and members voiced concerns regarding the breadth of support requirements within the network. Despite high levels of strategic stakeholder engagement, a percentage of micro-firm practitioners exited the network at this point. An emphasis on immediately applicable knowledge was very evident during this early stage, with requests to 'define the outcome and benefit of participating' and provide 'proof ... of environmentally-friendly practices working, being cost-effective and tangible'. Nonetheless, although members were cautious about committing to the network, citing that 'time is an issue', requests for the FLN hub to facilitate further discussions 'between [planned] meetings and seminars' demonstrated growing levels of enthusiasm and perceived value.

\section{An emergent community of practice}

Following a review meeting at the end of year one of the FLN, the authors organized focus groups to gain insights from theme champions regarding progress to date and proposed future interventions. Recurring requests to clarify the 'terminology of green and green innovation' were echoed here. Notably, champions provided local insights in relation to successful projects, and identified key individuals instrumental in their initiation and success, bridging knowledge exchange connections with the wider network (as outlined by Phillipson et al, 2006 and Reinl and Kelliher, 2014). Cyclical physical and virtual interventions followed with a series of generic and thematic seminars/workshops that facilitated crossborder and cross-disciplinary knowledge transfer and integration. Here, contemporary business processes and concepts were highlighted in best practice examples alongside stories of business failure. Collectively, these provided valuable learning experiences (as noted by Lee et al, 2005) that members could relate to as real working ideas (Fiol and Lyles, 1985).

FLN brokers observed an emerging learning curriculum (Lave and Wenger, 1991) as participants began to leverage the network:

'... We can approach professionals and consultants such as [the Managing Director] of the Green Hospitality Programme and [the Director] of Sustainable Tourism Ireland, also offered some important insights into the idea of green certification.' (Green tourism group facilitator)

Green technology practitioners requested a policy comparison of the UK and Ireland:

'Going green will save the business money but will Irish consumers understand it? How comparable are they to foreign tourists as regards appreciating green tourism??? ... making it work in the Irish marketplace!'

A 'walking tourism' seminar provided an opportunity for $80+$ stakeholders to hear examples of successful walking tourism initiatives. Fáilte Ireland (the Irish National Tourism Authority) representatives identified growing target markets of 'relatively affluent mature individuals and clubs/groups', outlining their potential value at ' $€ 8$ million Euros from overseas walking tourists'. Ideas for developing walking packages building on Ireland's strength of providing a warm welcome and Wales's strength of culture and heritage were discussed:

'Llwn Peninsula [Wales] with a coastal and Pilgrim trail marketing itself as a heritage destination, maximising the potential of museums and the Welsh language adding to the value of the experience.' 'Wicklow and Kerry [Irish counties] have passports that include discounts at local restaurants/accommodation providers etc.'

'The Beara-Breifne Way [Ireland] are using Stamps ... Link in with Fáilte Ireland and Discover Ireland to market abroad ... use case studies and Trip Advisor Badges.'

These activities permitted the development of strategic regional, national and cross-border knowledge exchange relationships. Building on the success of physical encounters, the virtual learning environment provided a forum to develop ideas and strategies further:

'Welsh participants were intrigued by the success of the Wrist Band scheme and sense of community 
ownership that is present in communities along Irish walking routes.' (Broker: virtual facilitator)

Prior to each online discussion, non-technical reading material and case studies were distributed by the FLN broker to prompt experience sharing, assisting in the creation of a 'common language' among network members (Swan et al, 2002).

\section{Engaging cross-border learning sets}

At the inaugural learning showcase event (LSE), many micro-firms reported feeling distant from their crossborder counterparts in both their approach to business development and the policy frameworks guiding their efforts. In response, an adapted year-two LSE incorporated a pre-event networking meeting to establish a rapport and allow micro-firms to explore areas of mutual interest. Following this change, a marked difference in the knowledge exchange dynamic was observed, with owner-managers committing to following up with one another once they returned to their own rural communities. Reflecting on the LSE objective, a government stakeholder remarked on [the FLN's] success:

'To get disparate businesses chatting to each other socially ... hearing about these ideas ... thinking of things in a different way ... and validating their own decisions so they [do not feel] alone.'

A micro-firm owner contemplating network relationships felt that,

'... the initial contact wasn't really followed up. I think the opportunity to network wasn't great maybe because we are so far removed in the industry as well. We're not all doing the same thing - what we're doing is not similar to the guy with the wind farm. So really there isn't a tie-in for us ... yet when we are brought together there's an opportunity for us to talk and learn.'

The FLN team acknowledged that the composition of the network was challenging in terms of engaging effective learning sets. In the themed sub-groups, a minority of participants requested that the network '... be mixed so that different skill sets and experience are reflected', suggesting a recognized need for multidisciplinary knowledge among the cohort, as predicted by Graci (2013) and Halme (2001). Others felt that larger network 'get-togethers' were 'overall too diverse', reinforcing Halme's (2001) advice for balanced learning set composition in pursuit of effective knowledge exchange.
In hindsight, members acknowledged that knowledge exchange relationships took time to develop:

'I think that this cross [border aspect] worked ... the Welsh are further ahead in certain areas than we are and maybe in other areas they're not so far ahead. I do think it's important we look outside Ireland. There weren't really any similar businesses to cultivate relationships with but this was probably our first step into the whole green environment of networking so maybe next time we might.'

Notably, topic-specific learning events that were applicable to individuals from different disciplines/ sectors (for example, resource efficiency and waste management) were deemed to be 'very informative'. B\&B operators, green technology providers, academic and industry stakeholders learned from one another and the micro-firms involved: 'made some great contacts ... which I hope will open new doors for me and my business'.

\section{Discussion and framework}

This paper explores the knowledge exchange criteria of rural micro-firms in a multidisciplinary cross-border FLN, and proposes a framework of knowledge exchange based on the findings (Figure 2). The observation and subsequent evaluation of a cross-border FLN over a three-year period permitted insights into the knowledge exchange criteria of rural micro-firms. The findings confirm the value of prolonged and cyclical stakeholder engagement in seeking to foster reciprocal knowledge exchange, transfer and exploitation in a micro-firm setting (Figure 2).

While the formation of effective learning sets could be viewed as somewhat unsuccessful in the early stages of GIFT, FLN brokers and micro-firm network members 'got to know one another' through a series of physical and virtual meetings where they developed an appreciation of the interdependencies of sustainability issues and 'requirements for collective action in their resolution' (Graci, 2013 , p 36) over time. Following early opportunities to negotiate green economy/sustainable development plans (Lave and Wenger, 1991; Lee et al, 2005), network member identities emerged (Wenger, 1998), and these were made visible across the wider community via business profiles and biographies (Parry, 2012). As a result of these initial efforts, network members began to configure into effective learning sets. Through sustained interaction and with ongoing FLN broker support (for example, through the codification and dissemination of diverse disciplinary knowledge), a common language developed within the GIFT network (Swan et al, 2002). 


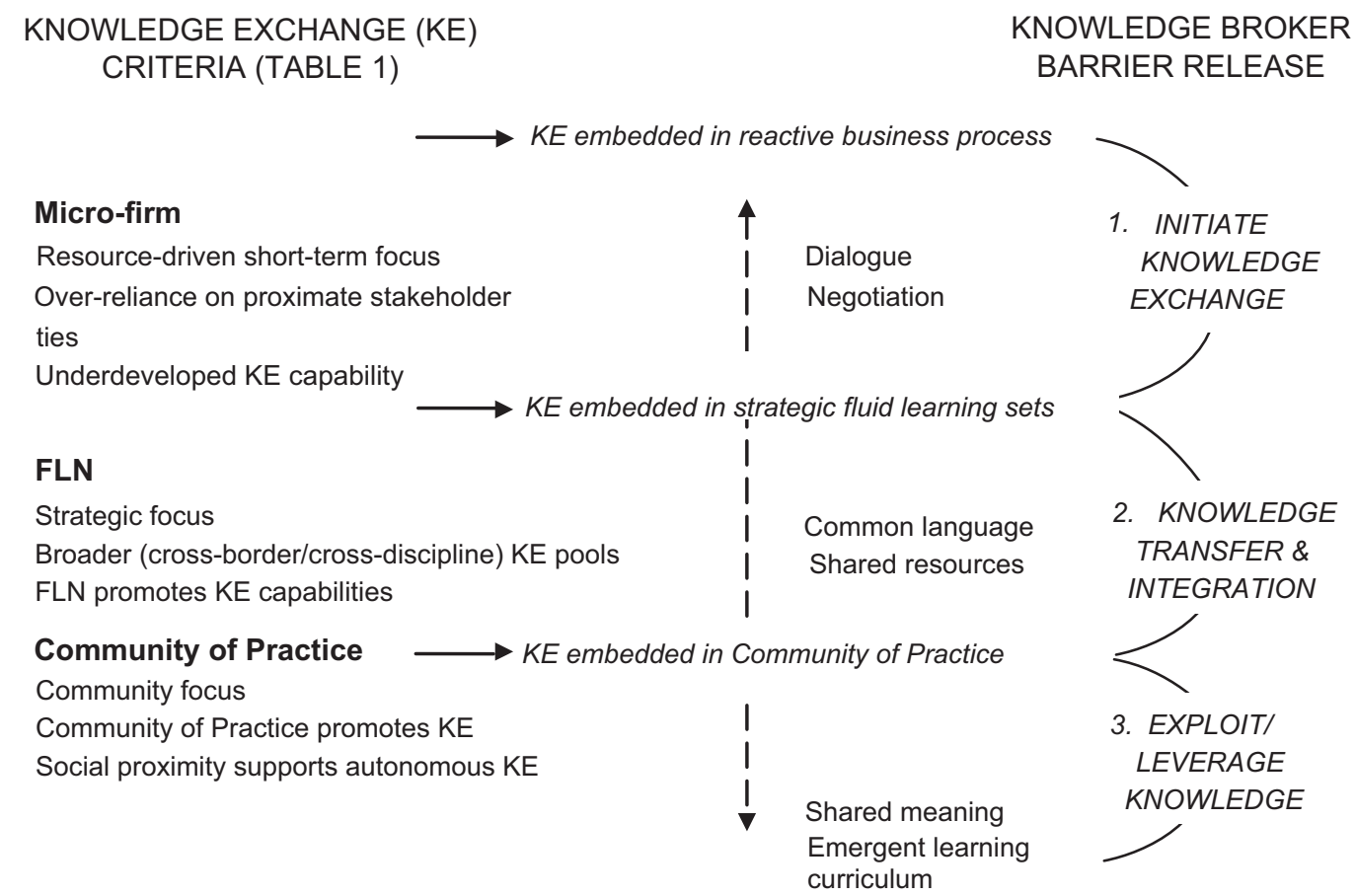

Figure 2. A framework of micro-firm knowledge exchange.

FLN brokers laid the foundations for knowledge transfer and integration by building a shared repertoire of resources (for example, case studies, reports and discussions) and providing facilitated virtual and physical spaces and events to support continued dialogue and negotiation. These interactions propelled further knowledge exchanges or rendered them spent or redundant, dependent on the nature and complexity of the knowledge required. Notably, successful outcomes were also reliant on the effective configuration of the learning set (Halme, 2001), and FLN broker support was significant with regard to moving numerous and at times divergent learning sets through the knowledge exchange phases illustrated in Figure 2. In time, a learning curriculum emerged as members began to leverage the network (Reinl and Kelliher, 2014; Wenger, 1998) and instigate self-led discussions, workshops and businessled academic projects. Network members participated in a number of different themed learning sets and interventions, jumping from one to the other depending on their requirements and availability. Ultimately, fluid learning sets supported by a strong FLN hub presence aided an emergent community of practice. Notably, the virtual learning environment provided the social proximity (Lave and Wenger, 1991; Miles and Tully, 2007; Reinl and Kelliher, 2010) to permit geographically distant or unavailable members to participate in the CoP.

The multi-level stakeholder (micro-firm, academia, industry, government) FLN approach provided for a comprehensive knowledge exchange/exploitation cycle in which initial experience sharing and idea generation could be framed by strategic inputs, permitting members to develop an appreciation of policy frameworks, regulations and strategic market trends. FLN brokers further enhanced this engagement, supporting the development of micro-firm skills through a series of academic/industry expert professional development workshops and in addition encouraging the exploitation of insights into business plans and funding applications to support micro-firm development. In so doing, they ensured that knowledge could be exploited on a community-wide/cross-border basis. Given the micro-firm resource constraints outlined previously (Devins et al, 2005; Kelliher and Reinl, 2009), it is unlikely that this level of knowledge exchange (Figure 2, phase 3 ) could have been reached in the absence of broker support (Reinl and Kelliher, 2014; Schaper, 2010). As such, a coordinating hub is essential to anchor and maintain a longer-term knowledge-sharing dynamic in a multi-level network of this nature.

The findings also demonstrate the value of sector/ community champions as in situ brokers in a green economy network context, specifically their role in bridging knowledge exchange connections from a local level and articulating local knowledge in a cross-border context. Distance between network members was not merely geographic; the findings suggest that disciplinary/sector-specific barriers also exist, but can be 
overcome with cyclical engagement efforts which are sensitive to social proximity requirements for effective knowledge exchange relationships. Notably, as knowledge exchange relationships with the FLN support hub became more established, members moved more readily into learning sets/arenas they had previously been reluctant to enter.

\section{Conclusion and recommendations}

The aim of this research was to explore multidisciplinary cross-border knowledge exchange criteria among rural micro-firms in a facilitated learning network (FLN) in Ireland and Wales and to offer a framework of cross-border knowledge exchange based on the findings. The knowledge exchange criteria illustrated in Figure 2 suggest that ongoing cyclical engagement in physical and virtual forums promoted knowledge flows (Lave and Wenger, 1991), while the virtual learning environment was instrumental in facilitating the social proximity required to underpin shared meaning (Lave and Wenger, 1991; Miles and Tully, 2007; Reinl and Kelliher, 2010) within a crossborder CoP.

Micro-firm owners/managers can use the CoP as a conduit through which they can exploit and leverage knowledge in pursuit of business development. However, given their propensity for immediate business solutions, 'unlearning' established ways of acquiring knowledge is necessary, and a structured academic-led FLN is valuable with regard to developing the skills and supporting the behavioural changes required to enable micro-firms to exploit and commercialize new ideas. Ideally, learning sets should comprise broad stakeholder bases (in recognition of the diverse and connected sectors/discipline bases that comprise the green economy) and facilitated engagement on a continuous and interim basis as appropriate (Jack et al, 2004; Reinl and Kelliher, 2014). These learning sets should be fluid and permit flexible engagement for resource-constrained and geographically distant micro-firm owners/managers. The findings indicate that a strong broker relationship is essential in supporting an emergent community of practice in this context, particularly in the coordination of phases 1 and 2 of the knowledge exchange process (Figure 2).

This study contributes to limited research on crossborder knowledge exchange, which has focused almost exclusively on larger firms in the same or related industries and disciplines. The findings are of specific value to rural micro-firm owner-managers and supporting government and industry agents seeking to maximize knowledge exchange in pursuit of green economic development. Further research might consider the sustainability of knowledge exchange within such a CoP, once funded FLN support ceases.

\section{Acknowledgments}

The authors wish to acknowledge the European Regional Development Fund (ERDF) through the Ireland Wales Programme (INTERREG 4A) which provided valuable funding for this research study. An earlier version of this paper was presented at the Global Conference on Business, Economics, Management and Tourism, Prague, Czech Republic, November 2014. The authors would like to acknowledge the support of INTERREG in this research.

\section{References}

Aylward, E. (2012), 'Collaborative rural networks (CRNs): an examination of the roles and relationships between regional stakeholders', PhD thesis, Waterford Institute of Technology, Waterford.

Bessant, J., and Tsekouras, G. (2001), 'Developing learning networks', Al and Society, Vol 15, No 1/2, pp 82-98.

Breschi, S., and Lissoni, F. (2003), Mobility and Social Networks: Localised Knowledge Spillovers Revisited, Discussion Paper, Università Commerciale 'Luigi Bocconi', Milan.

Brouder, P., and Eriksson, R.H. (2013), 'Staying power: what influences micro-firm survival in tourism?' Tourism Geographies: An International Journal of Tourism Space, Place and Environment, Vol 15, No 1, pp 125-144.

Chell, E., and Baines, S. (2000), 'Networking, entrepreneurship and micro-business behaviour', Entrepreneurship and Regional Development, Vol 12, No 3, pp 195-215.

Comhar Sustainable Development Council (2009), 'Towards a green new deal for Ireland', website: http://files.nesc.ie/ comhar_archive/Comharper cent20Reports/ Comhar_25_2009.pdf (accessed 12 February 2014).

Cunliffe, A.L. (2004), 'On becoming a critically reflexive practitioner', Journal of Management Education, Vol 28, No 4, pp 407-426.

Deavers, K. (1992), 'What is rural?' Journal of Policy Studies, Vol 20, No 3, pp 184-189.

Devins, D., Gold, J., Johnson, S., and Holden, R. (2005), 'A conceptual model of management learning in micro businesses - implications for research and policy', Education and Training, Vol 47, No 8/9, pp 540-551.

Döring, T., and Schnellenbach, J. (2006), 'What do we know about geographical knowledge spillovers and regional growth? A survey of the literature', Regional Studies, Vol 40, No 3, pp 375-395.

Drda-Kühn, K., and Wiegand, D. (2010), 'From culture to cultural economic power: rural regional development in small German communities', Creative Industries Journal, Vol 3, No 1, pp 8996.

Eisenhardt, K.M. (1989), 'Building theories from case study research', Academy of Management Review, Vol 14, No 4, pp 532-550.

Erkuş-Öztürk, H. (2009), 'The role of cluster types and firm size in designing the level of network relations: the experience of the Antalya tourism region', Tourism Management, Vol 30, pp 589-597.

European Commission (2011), Observatory of European SMEs, website: http://ec.europa.eu/enterprise/policies/sme/factsfigures-analysis/index_en.html (accessed 30 January 2014).

Fiol, C.M., and Lyles, M.A. (1985), 'Organisational learning', Academy of Management Review, Vol 10, No 4, pp 803-813. 
Florén, H. (2003), 'Collaborative approaches to management learning in small firms', Journal of Workplace Learning, Vol 15, No 5, pp 203-218.

Florén, H., and Tell, J. (2004), 'The emergent prerequisites of managerial learning in small firm networks', Leadership and Organisational Development Journal, Vol 25, No 3, pp 292307

Freel, M.S. (1999), 'Where are the skills gaps in innovative small firms?' International Journal of Entrepreneurial Behaviour and Research, Vol 5, No 3, pp 144-154.

Garavan, T., McCarthy, A., McMahon, J., and Gubbins, C. (2004), 'Management development in micro and small firms in Ireland: linking management development practices to firm size, strategic type, HRM orientation and owner-manager espoused values', in Stewart, J., and Beaver, G., eds, HRD in Small Organisations: Research and Practice, Routledge, New York, pp 285-312.

Ghaye, T., and Lillyman, S. (1997), Learning Journals and Critical Incidents: Reflective Practice for Health Care Professionals, Quay Books, London.

Government of Ireland (2013), Progress Report on Growth and Employment in the Green Economy in Ireland, Government of Ireland, Dublin.

Graci, S. (2013), 'Collaboration and partnership development for sustainable tourism', Tourism Geographies: An International Journal of Tourism Space, Place and Environment, Vol 15, No $1, \mathrm{pp} 25-42$.

Halme, M. (2001), 'Learning for sustainable development in tourism networks', Business Strategy and the Environment, Vol 10, No 2, pp 100-114.

Haugen Gausdal, A. (2008), 'Developing regional communities of practice by network reflection: the case of the electronics industry', Entrepreneurship and Regional Development, Vol 20, No 3, pp 209-235.

Herr, K., and Anderson, G.L. (2005), The Action Research Dissertation: A Guide for Students and Faculty, Sage, London.

Jack, S.L., Dodd, S.D., and Anderson, A.R. (2004), 'Social structures and entrepreneurial networks: the strength of strong ties', International Journal of Entrepreneurship and Innovation, Vol 5, No 2, pp 107-120.

Kearney, A., Harrington, D., and Kelliher, F. (2014), 'Exploiting managerial capability for innovation in a micro-firm context', European Journal of Training and Development, Vol 38, pp 95-117.

Kelliher, F., Aylward, E., and Reinl, L. (2014), 'The impact of knowledge hoarding on micro-firm learning network exchange', in Machado, C., and Davim, J.P., eds, Transfer and Management of Knowledge (Cognitive Science and Knowledge Management Series), ISTE Ltd and John Wiley \& Sons, Chichester, pp 1-20.

Kelliher, F., Foley, A., and Frampton, A.M. (2009), 'Facilitating small firm learning networks in the Irish tourism sector', Journal of Tourism and Hospitality Research, Vol 9, No 1, pp 80-95.

Kelliher, F., and Reinl, L. (2009), 'A resource-based view of micro-firm management practice', Journal of Small Business and Enterprise Development, Vol 16, No 3, pp 521-532.

Lave, J., and Wenger, E. (1991), Situated Learning. Legitimate Peripheral Participation, University of Cambridge Press, Cambridge.

Lee, J., Árnason, A., Nightingale, A., and Shucksmith, M. (2005), 'Networking: social capital and identities in European rural development', Sociologia Ruralis, Vol 45, No 4, pp 269-283.

Mäkinen, H. (2002), 'Intra-firm and inter-firm learning in the context of start-up companies', International Journal of Entrepreneurship and Innovation, Vol 3, No 1, pp 35-43.

Marsden, T., Lowe, P., and Whatmore, S. (1990), Rural Restructuring: Global Processes and their Responses, David Fulton Publishers, London.

Miles, N., and Tully, J. (2007), 'Regional development agency policy to tackle economic exclusion? The role of social capital in distressed communities', Regional Studies, Vol 41, No 6, pp 855-866.

Morrison, A., Lynch, P., and Johns, N. (2004), 'International tourism networks', International Journal of Contemporary Management, Vol 16, No 3, pp 197-202.

Murdoch, J. (2000), 'Networks: a new paradigm of rural development?' Journal of Rural Studies, Vol 16, No 4, pp 407-419.

Noel, T.W., and Latham, G.P. (2006), 'The importance of learning goals versus outcome goals for entrepreneurs', International Journal of Entrepreneurship and Innovation, Vol 7, No 4, pp 213-220.

Parry, S. (2012), 'Going green: the evolution of micro-business environmental practices', Business Ethics: A European Review, Vol 21, No 2, pp 220-237.

Phillipson, J., Bennett, K., Lowe, P., and Raley, M. (2004), 'Adaptive responses and asset strategies: the experience of rural micro-firms and foot and mouth disease', Journal of Rural Studies, Vol 20, No 2, pp 227-243.

Phillipson, J., Gorton, M., and Laschewski, L. (2006), 'Local business co-operation and the dilemmas of collective action: rural micro-business networks in the north of England', Sociologia Ruralis, Vol 46, No 1, pp 40-60.

Reason, P., and Bradbury, H. (2006), Handbook of Action Research, Sage, London.

Reinl, L., and Kelliher, F. (2010), 'Cooperative micro-firm strategies: leveraging resources through learning networks', International Journal of Entrepreneurship and Innovation, Vol 11, No 2, pp 141-150.

Reinl, L., and Kelliher, F. (2014), 'The social dynamics of microfirm learning in an evolving learning community', Tourism Management, Vol 40, pp 117-215.

Revans, R.W. (1998), ABC of Action Learning, Lemos and Crane, London.

Rigg, C. (2008), 'Action learning for organisational and systematic development: towards an understanding of "l" and "we", Action Learning: Research and Practice, Vol 5, No 2, pp 105116.

Saxena, G., and Ilbery, B. (2008), 'Integrated rural tourism: a border case study', Annals of Tourism Research, Vol 35, No 1, pp 233-254.

Schaper, M. (2010), Making Ecopreneurs: Developing Sustainable Entrepreneurship, 2 ed, Gower/Ashgate Publishers, Farnham, and Burlington, VT.

Susman, G., and Evered, R. (1978), 'An assessment of the scientific merits of action research', Administrative Science Quarterly, Vol 23, No 4, pp 582-603.

Swan, J., Scarbrough, H., and Robertson, M. (2002), 'The construction of communities of practice in the management of innovation', Management Learning, Vol 33, No 4, pp 477-496.

Tell, J. (2000), 'Learning networks - a metaphor for inter organizational development in SMEs', Enterprise and Innovation Management Studies, Vol 1, pp 303-317.

Toiviainen, H. (2007), 'Inter-organizational learning across levels: an object oriented approach', Journal of Workplace Learning, Vol 19, No 6, pp 343-358.

Trehan, K., and Pedler, M. (2011), 'Cultivating foresight and innovation in action learning: reflecting ourselves: reflecting with others', Action Learning: Research and Practice, Vol 8, No 1, pp 1-4.

United Nations Environment Programme - UNEP (2011), Towards a Green Economy: Pathways to Sustainable Development and Poverty Eradication, A Synthesis for Policy Makers, pp 1-52, website: http://www.unep.org/ greeneconomy/Portals/88/documents/ger/ GER_synthesis_en.pdf (accessed 14 January 2014).

Uzzi, B. (1997), 'Social structure and competition in inter-firm networks: the paradox of embeddedness', Administrative Science Quarterly, Vol 42, No 1, pp 35-67.

von Malmborg, F. (2007), 'Stimulating learning and innovation in networks for regional sustainable development: the role of local authorities', Journal of Cleaner Production, Vol 15, No 17, pp 1730-1741. 
Welsh Government (2009), Capturing the Potential: A Green Jobs Strategy for Wales, Crown Publishers, Cardiff.

Wenger, E. (1998), Communities of Practice: Learning, Meaning and Identity, Cambridge University Press, New York.

Wenger, E.C., Mc Dermott, R., and Snyder, W.M. (2008),
Communities of Practice: Learning, Meaning and Identity, Cambridge University Press, Cambridge.

Wheelock, J., and Baines, S. (1998), 'Dependency or selfreliance? The contradictory case of work in UK small business families', Journal of Family and Economic Issues, Vol 19, No 1, pp 53-73 